THE AFTER RESULTS OF CATARACT EXTRACTION

BY

R. C. DAVENPORT

MOORFIEL.DS RESEARCH SCHOLAR

In Vol. XIV of the Ophthalmic Hospital Reports Devereux Marshall published an analysis of the results of all the cataract extraction operations performed at Moorfields in the five years, 1889-1893 inclusive. I have collected and analyzed those done in the seven years, 1919-1925 inclusive, with a view to seeing how the results compare, more especially as regards the more frequently used extraction operations without complete iridectomy. The total number Marshall collected was 1,519 ; I have found the total in the seven years I have gone into to be 2,368. This number comprises all I can find where extraction was performed for a cataract other than traumatic, with the exclusion of those in which extraction was performed, or attempted, by Barraquer's method, the results of which have already been published ${ }^{(1)}$.

The numbers in each year are as follow :

$\begin{array}{rlll}1919 & \ldots & \ldots & 383 \\ 1920 & \ldots & \ldots & +35 \\ 1921 & \ldots & \ldots & 352 \\ 1922 & \ldots & \ldots & 272 \\ 1923 & \ldots & \ldots & 284 \\ 1924 & \ldots & \ldots & 300 \\ 1925 & \ldots & \ldots & 342 \\ \text { Average } & \ldots & \ldots & 388\end{array}$ Barraquer's method used

Of the total there were:

$$
\begin{aligned}
& \text { Extractions with Preliminary Iridectomy } \quad \ldots \quad \text {. . } \quad 99
\end{aligned}
$$

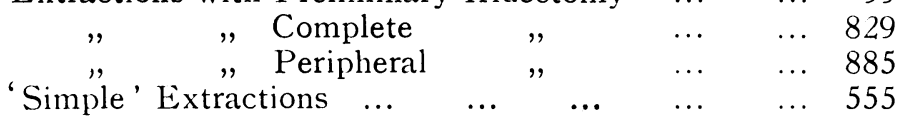

Thus, of the total nearly 25 per cent. were "simple" extractions, a much higher proportion than in Marshall's series. The extraction with peripheral iridectomy was not then employed but is more and more frequently used now at Moorfields-the figures for the last two years showing a greater usage of this technique than any other, viz., 290 out of a total of 642 .

The simple extraction, on the other hand, is less frequently employed than in the earlier years of the series.

The preliminary iridectomy operation is used but little now. In many of the cases previous iridectomy was done for a diseased condition, in others because a morbid state was suspected or 
present so that advantage might be gained from the presence of an iridectomy and information gleaned as to the reaction of the eye to operation. I have not found it possible to separate the various conditions clearly so have decided to class together all the cases in which iridectomy was performed-for whatever cause-as a separate operation prior to the actual lens extraction.

The sex of the patients was as follows : Males 46.1 per cent., Females 53.9 per cent.

The Ages :

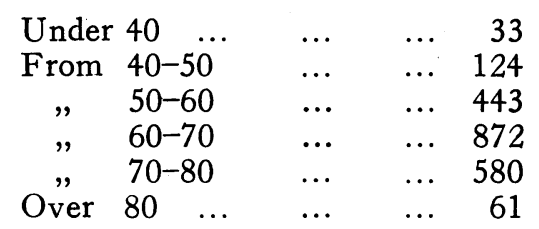

In 25 cases I have not been able to find the age of the patient. I have been able to get visual and other records in 2,244 cases out of a total number of 2,368. The difference between the two figures is made up as follows :

Died from pneumonia, heart failure, diabetic coma, etc. $\quad \ldots \quad 12$

$\begin{array}{llllllllll}\text { Insane } & \ldots & \ldots & \ldots & \ldots & \ldots & \ldots & \ldots & \ldots & 8\end{array}$

$\begin{array}{lllllll}\text { No visual record obtainable } & \ldots & \ldots & \ldots & \ldots & \ldots & \ldots \\ \end{array}$

There is no doubt that many in the last class had good vision resulting from the operation, but I have thought it best to exclude them from the figures, though Marshall included those cases where it seemed likely that they would fall into a certain category of his analysis.

\section{Results in mass}

I have divided the visual results, as a criterion of the measure of success of the operation into five groups :

$$
\begin{array}{ccccc}
\text { A } & \ldots & \ldots & \text { Vision } 6 / 6 \text { part or better } \\
\text { B } & \ldots & \ldots & " & 6 / 12, " \text { " } " \\
\text { C } & \ldots & \ldots & " & 6 / 60 \text { or better } \\
\text { D } & \ldots & \ldots & \text { '" } & \text { P.L. " " " } \\
\text { E } & \ldots & \ldots & \text { Excisions and no. P.L. }
\end{array}
$$

This is a rather more critical subdivision than that used by Marshall, but I think as such it brings out certain features. It is, of course, realized that factors other than the state of the eye enter into the visual result obtained, particularly the intelligence 
and effort of the patient. But the degree of care employed by the observer in obtaining the most suitable correction for the patient, combined with the degree of insistence shown in eliciting the best subjective result, both make a considerable difference to the figures of a more critical review. The calibre of a surgeon's assistant often plays a part in such records.

The figures are as follow :
$\left.\begin{array}{lllll}\text { A }(6 / 6 \text { part. }+) & 610 & \ldots & \ldots & 27.18 \% \\ \text { B }(6 / 12 \text { part. }+) & 932 & \ldots & \ldots & 41.53 \%\end{array}\right\} 68.71 \%$
C $(6 / 60+) \quad 442 \quad \ldots \quad \ldots \quad 19.70 \%$
$\begin{array}{lllll}\text { D (P.L. +) } & 210 & \ldots & \ldots & 9.36 \%\end{array}$
E (Excisions 50) No P.L. 10) $\} 2.5 \%$ of total operations

If a successful result be taken as that in which at least $6 / 60$ vision is obtained it will be seen that the figure is 88.41 per cent. Marshall, in his series, showed a figure of 89.7 per cent. for this category so that the results are at least not better in the main for recent years.

The results of A. and B. groups (which might be termed very good and good) are 68.71 per cent. Marshall showed 76 per cent. with $6 / 18$ or better. If the cases of $6 / 18$ are added in this series to those in groups A. and B. the figures are 76.1 per cent.strikingly close to his, although the percentage is greater in the highest groups as compared with his results, which were A. 22.7, and B. 35.4.

Where the vision is not as good as $6 / 60$ the result must be called "poor" at least. I have analyzed the 210 cases in this group D. showing where possible the cause of the poor result.

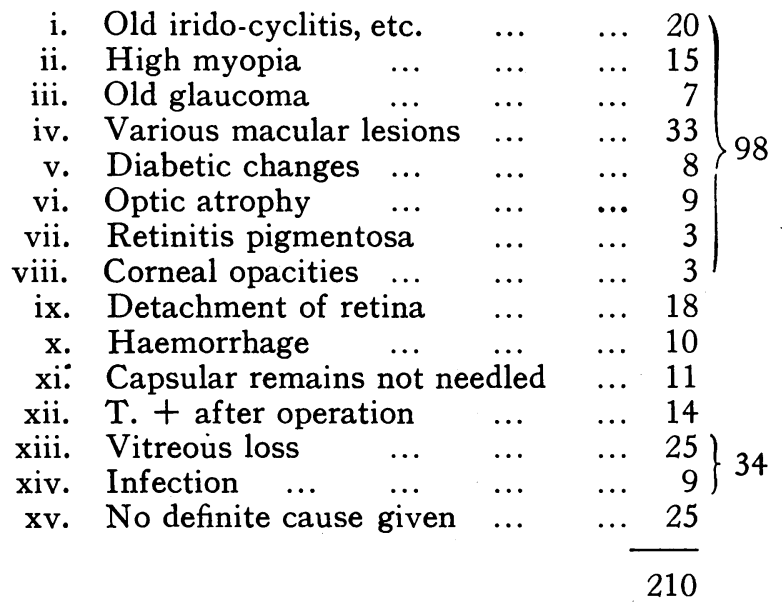


From this it will be seen that in nearly 50 per cent. of the cases a pre-existing lesion can definitely be held responsible for the poor final result of the operation, as regards visual acuity.

Group E., comprising 10 blind eyes and 50 excisions can be analyzed as below :

$\left.\begin{array}{lcccccc}50 \text { excisions } & \ldots & \multicolumn{5}{c}{2.1 \text { per cent. of total operations. }} \\ \begin{array}{l}\text { Suppuration } \ldots \\ \text { Large loss of vitreous (infection playing a }\end{array} & \ldots & \ldots & 20 \\ \text { probably in loss of eye) } \ldots & \ldots & \ldots & \ldots & 7\end{array}\right\} 1.14 \%$

Of the suppurative cases, 6 were known to be diseased eyes prior to operation, 2 being diabetic cases, and 2 glaucoma, 1 high myopia, 1 irido-cyclitis, and 1 nystagmus.

Marshall's figures were :

$1.71 \%$ suppurations after extraction
so that the losses from acute infection appear considerably lower
in recent years. On the other hand his percentage of excisions
was only 1.9.
The 10 cases of total blindness resulted from severe infection,
large vitreous loss and detachment of retina, though some of the
latter supervened in eyes which had had successful extraction of
cataract with subsequent good vision before detachment of the
retina appeared.

\section{Visual results subsequent to the various types of operations}

In these tables I have excluded the cases where preliminary iridectomy was performed as in these the high proportion of morbid states prior to operation in my opinion makes a comparison of results worthless.

\begin{tabular}{|c|c|c|c|c|c|c|c|}
\hline & & Totals & A & B &. $\mathrm{C}$ & $\mathrm{D}$ & $\mathrm{E}$ \\
\hline Simple Extractions & $\ldots$ & 524 & 160 & 233 & 89 & 35 & 7 \\
\hline With Peripheral Iridectomy & $\ldots$ & 846 & 274 & 371 & 149 & 36 & 16 \\
\hline With Complete Iridectomy & $\ldots$ & 784 & 171 & 317 & 189 & 81 & 28 \\
\hline
\end{tabular}


After Results of Cataract Extraction

Percentage Table.

\begin{tabular}{|c|c|c|c|c|c|c|}
\hline & & Totals & A $\quad$ B & $\mathrm{C}$ & $\mathrm{D}$ & $\mathrm{E}$ \\
\hline Simple Extractions & $\cdots$ & 524 & $\frac{30.5344 .4}{74.93}$ & 17.02 & 6.70 & 1.33 \\
\hline With Peripheral Iridectomy & $\ldots$ & 846 & $\frac{32.3843 .85}{76.23}$ & 17.61 & 4.25 & 1.89 \\
\hline With Complete Iridectomy & & 784 & $\underbrace{21.8 \quad 40.42}_{62.22}$ & 23.85 & 10.33 & 3.57 \\
\hline
\end{tabular}

It is obvious from these tables that the results in the cases where complete iridectomy is done are appreciably worse than in the other groups. At the same time there is no doubt that iridectomy is often used where any danger is suspected, e.g., in myopic eyes, or eyes that have been subjects of inflammation. The final results would, therefore, be less satisfactory in such cases. These may be sufficient to account for the difference between the figures. But there is reason to think that the figures are evidence for the contention that the intact pupillary rim prevents capsule becoming entangled in the wound and thereby lowers the risk of chronic infection which, though not necessarily a danger to the existence of the eye, lowers its visual acuity by the production of exudation to cloud the transparent media. That such may be the case is further suggested by the fact that the figure for group E for blind or excised eyes is more than twice that in the other types.

The figures for simple extractions and those with peripheral iridectomy so nearly agree that I doubt if any differential criticism has any value, though it is interesting to see that the figure in group E. for simple extractions, is lower than that of either of the others-a fact of some interest in view of the much greater frequency of prolapse of iris in this type of operation.

With this figure excepted the figures for peripheral iridectomy are, however, slightly the better of the two in the three categories (A., B.), C., and D.

It is not possible to compare these figures with Marshall's except to state that the figures of groups A. and B. are as good as his with the addition of $6 / 18$. But as from these operations some of the doubtful eyes are probably omitted, it hardly seems a sound comparison. He, too, pointed out that in his series the figures for extraction without iridectomy were appreciably better than those for the combined operation although the risk of prolaps: and subsequent damage was so much greater. 
PROLAPSE OF IRIS

\begin{tabular}{c|c|c|c}
\hline Total. & $\begin{array}{c}\text { With complete } \\
\text { Iridectomy. }\end{array}$ & $\begin{array}{c}\text { With peripheral } \\
\text { Iridectomy. }\end{array}$ & $\begin{array}{c}\text { Without } \\
\text { Iridectomy. }\end{array}$ \\
\hline 163 & 42 & 50 & 71 \\
$6.88 \%$ & $4.52 \%$ & $5.65 \%$ & $12.8 \%$ \\
\hline
\end{tabular}

Visual Results after Prolapse.

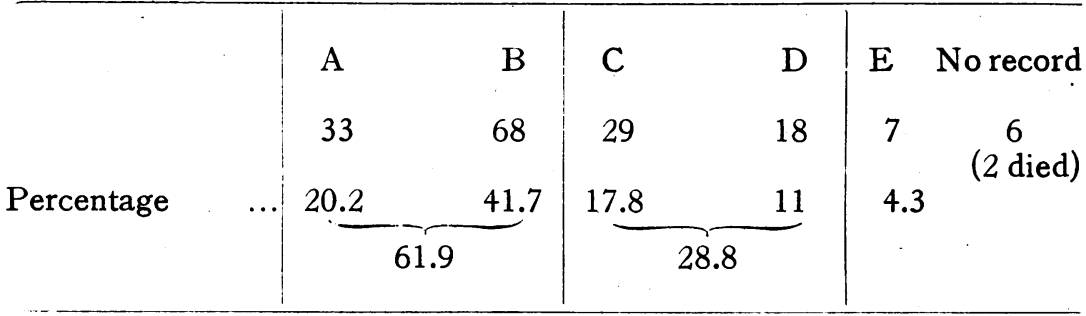

Examination of these figures is of some interest. As is to be expected the percentage of prolapses in simple extractions is considerably higher than where iridectomy has been done. But the figures for iridectomy are high so that the total percentage is more than twice that recorded in Marshall's series where the simple extractions show 13.86 per cent., but the percentage after the combined operation is only 0.87 . It might be thought that the small peripheral iridectomy is only a partial safeguard, but the figures in this operation are but little higher than those for complete iridectomy which are themselves so much higher than in Marshall's series.

It is hard to find any definite reason for the increased frequency of this accident. It may be that the extraction of immature cataract, so much more freely done now, increases the amount of soft lens matter left in the eye and this, on swelling, makes the risk of prolapse greater.

But if the frequency of prolapse is greater its effects on the final result do not seem as bad as has been held to be the case. Where there is a wide prolapse which is excised at once, the majority of results differ in no way from the normal. But a prolapsed pillar or a late prolapse undoubtedly leads to infection. Taking the results of the table as a whole it is clear that risk of suppuration and infection is only slightly greater, and that the added danger of a second operation is not so great as to lower very appreciably the final visual result. 
It may only be coincidence that two of the deaths occurred after prolapse of the iris. But it must be true that a second operation, either with general anaesthesia or associated with pain under local anaesthesia, adds to the risk of heart failure or pneumonia in an elderly patient.

\section{Vitreous loss}

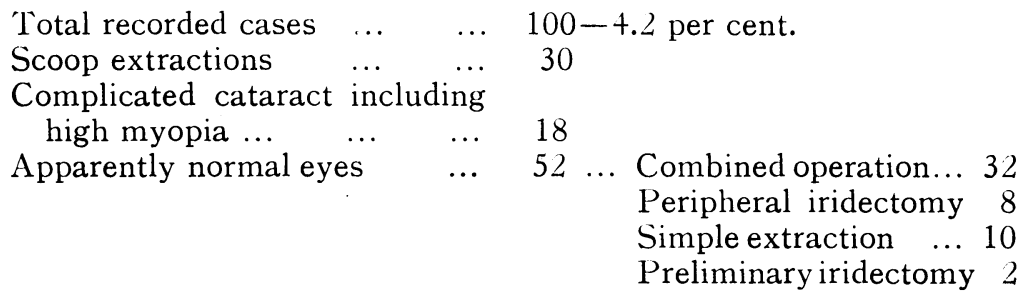

It cannot be said that the percentage of vitreous loss is highMarshall's figure is 4.27 , strikingly similar. It is perhaps a little unexpected to find that more than half were in apparently normal eyes, but the notes are too limited to be sure of this point or to glean any reasons. The striking fact is that the numbers in the combined operation are relatively so much greater than in other operations. This gives support to the idea that many of the eyes were not normal, or that the patient was a difficult subject. Probably the latter fact is the more important for it is hard to see why vitreous should be more often lost under normal conditions where an iridectomy has cleared the way for the lens than where the intact iris would supposedly demand greater pressure and more manipulations in the delivery of a lens. Marshall found the same fact in his series although the number of simple extractions was so much smaller. He suggested that such a result was entirely due to the fact that where the simple operation was done the eye was a "picked case" and a morbid state of vitreous or ill-behaved patient unlikely. I am not sure that so much reliance can be placed as before on such factors as in many cases lens delivery through an intact pupil is an absolute routine unless there is a very definite contra-indication. But even if this is the case it means that the obviously doubtful eye is left for the combined operation, and in such an eye vitreous loss may be more readily expected.

PERCENTAGE OF VISUAL RESUlts AFTER VITREOUS LOSS

\begin{tabular}{|c|c|c|c|c|c|}
\hline A & $\ldots$ & $\ldots$ & \multicolumn{3}{|c|}{3 per cent. } \\
\hline B & $\ldots$ & $\ldots$ & 24 &, & , \\
\hline $\mathrm{C}$ & $\ldots$ & $\ldots$ & 22 & 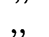 & 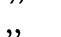 \\
\hline D & $\ldots$ & $\ldots$ & 25 & , & , \\
\hline E & $\ldots$ & $\ldots$ & 17 & ," & $"$ \\
\hline record & $\cdots$ & $\ldots$ & 9 & , & , \\
\hline
\end{tabular}


It is obvious that these are very much lower than the normal. Only 49 per cent. are $6 / 60$ or better, and 17 per cent. have no perception of light or come to excision. In the face of such results it is impossible to regard the accident as of no great importance although its frequency and poor final result are so much influenced by the existence of an unhealthy state in the eye or patient prior to operation.

Marshall's figures are very much better than those given here. Forty-eight per cent. are $6 / 18$ or better, and 73 per cent. are $6 / 60$ or better. He makes no analysis of the cases, merely stating that many were of unhealthy type, and it is possible that more unhealthy eyes are now operated on in the hopes of some, if not great, improvement as a final result, than was the case in the years he reviewed.

\section{Sympathetic ophthalmitis}

Only four cases are recorded where this tragic event followed cataract extractions or needling. Marshall showed eight in his series.

Of the four, in one case both eyes were excised, in another one eye excised, and the sympathizing eye had perception of light vision. In the third both were saved with perception of light vision, in the fourth the inflammation was so slight in the exciting eye that the end result was $6 / 6$ vision, whereas the sympathizing eye was excised owing to its destruction by the severity of the inflammation. This is a somewhat striking result. Little heed was paid to a mild attack of cyclitis in the exciting eye which quietened at once. But the patient returned in three months with that eye still quiet and the sympathizing eye in a hopeless state.

\section{Tension raised after extraction and needling}

It is hard to get accurate figures of this. In quite a number a temporary + tension is noted on one or two occasions and then no more, with a good visual result. But in 14 cases there was sufficient + tension to lower the visual acuity below $6 / 60$, and in four cases excision was the only treatment that would relieve the symptoms.

\section{After-cataract needling}

There are 1,479 needling operations recorded subsequent to the extractions of this series, giving a percentage of 62.4. No case of suppuration occurred, though five cases of chronic infection leading to excision are recorded. Others are noted with some degree of infection, but it is not easy to differentiate either these or the more serious ones from most extraction infections. In some 
there has been definite inflammation lit up by needling; in others infection is only noted first after the needling. The same holds for raised tension which has been considered above.

Marshall showed only 26.49 per cent. of needlings-a very much smaller figure. It appears necessary to give a little explanation as to why, with so much smaller a number of needlings, his results in the main are very similar to those in this series. In both series about $\tilde{6} 6$ per cent. show $6 / 18$ or better, but if this be subdivided it will be seen that in the higher groups there is a marked difference. I have collated his figures as accurately as possible.

\author{
Marshall. 6/6+, 22.7 per cent. \\ $6 / 12+, 35.4,,$, \\ $6 / 18+, 18$ per cent. approximately. \\ This series $6 / 6+, 27.18$ per cent. \\ $6 / 12+, 41.53, "$, \\ $6 / 18+, 7.4$ per cent. approximately.
}

The very much greater frequency with which needling is performed now must account for the much better results in the subdivision of the higher grades of visual acuity after extraction. Needling is now so much less frequently followed by any bad results that it is more and more lightly undertaken, even to a point of needling every eye after extraction--almost as a "prophylactic" against the development of a membrane dense enough to obstruct vision. At the same time I would suggest that there is a greater need for needling now. When a hard mature lens was extracted any membrane left was likely to be so thin in many cases that $6 / 18$ or $6 / 12$, or even better vision resulted. Now that extraction is undertaken much earlier, in many cases, the chance of leaving soft lens matter, in spite of careful toilet or irrigation, is increased. The risk of infection is probably no greater, but the resulting after-cataract is often such as to give visual acuity well below $6 / 18$. On needling, this is of course readily cleared from the pupil, with resulting good vision. These factors, I think, probably explain the very much larger percentage of needling operations in this series.

As Moorfields Research Scholar I have had full access to the notes of the patients, and I wish to thank the surgical staff at Moorfields for permission to collect and publish the facts in this paper.

\title{
REFERENCES
}

1. Foster Moore.-Trans. Ophthal. Soc. U.K., Vol. XLIII, p. 223.

Greeves.-Trans. Ophthal. Soc. U.K., Vol, XLIII, p. 223. 